\title{
Pemanfaatan Algortima K-Means Clustering Sebagai Pengamanan Pencurian Buah Kelapa Sawit Se-Distrik Tandun PT. Perkebunan Nusantara V
}

\author{
Tengku Mohd Diansyah, Aristu Fahri Tanjung, Rismayanti \\ Program Studi Teknik Informatika, Universitas Harapan Medan, Sumatera Utara, Indonesia \\ Email: aristufahri12@gmail.com,dian.10.22@gmail.com, risma.stth@gmail.com
}

\begin{abstract}
Abstrak
Pencurian buah kelapa sawit di PT. Perkebunan Nusantara V masih sering terjadi, khususnya pada salah satu distrik yaitu Distrik Tandun yang memiliki 6 kebun kelapa sawit dan karet. Tingginya tingkat pencurian buah kelapa sawit menyebabkan penurunan jumlah produksi buah kelapa sawit dan inti sawit. Pada penelitian ini membahas mengenai penggunaan algoritma K-Means Clustering sebagai salah satu algoritma data mining dalam melakukan pengelompokan data pencurian kelapa sawit yang berada pada daerah perkebunan kelapa sawit Se-Distrik Tandun. Dengan sejumlah data pencurian, penelitian ini memungkinkan ditemukannya potensi terjadinya pencurian buah kelapa sawit lokasi perkebunan kelapa sawit dengan tingkatan rendah, sedang, dan tinggi. Perhitungan algoritma K-Means Clusering menggunakan 3 parameter pendukung yaitu luas wilayah setiap afdeling, jumlah buah yang berhasil diselamatkan, dan jumlah buah yang telah dicuri. Setelah mengetahui lokasi-lokasi yang berpotensi terjadinya pencurian buah kelapa sawit, perusahaan dapat melakukan strategi untuk melakukan pengamanan terhadap lokasi yang berpotensi tersebut.
\end{abstract}

Kata kunci: Data Mining, Clustering K-Means, Pencurian, Kelapa Sawit

\begin{abstract}
Oil palm fruit theft at PT. Perkebunan Nusantara V still occurs frequently, especially in one district, Tandun District which has 6 oil palm and rubber plantations. The high rate of theft of oil palm fruit causes a decrease in the production of oil palm fruit and palm kernel. This study discusses the use of the K-Means Clustering algorithm as one of the data mining algorithms in grouping data on palm oil theft in the oil palm plantation area of Tandun District. With a number of theft data, this study enables the discovery of the potential for theft of oil palm fruit in the location of oil palm plantations at low, medium and high levels. K-Means Clusering algorithm calculation uses 3 supporting parameters, namely the area of each afdeling, the number of fruits that have been saved, and the number of fruits that have been stolen. After knowing the locations that have the potential for theft of oil palm fruit, the company can implement a strategy to safeguard those potential locations.
\end{abstract}

Keywords: Data Mining, Clustering, K-Means, Theft, Palm Oil.

\section{PENDAHULUAN}

PT. Perkebunan Nusantara V adalah salah satu perusahaan Badan Usaha Milik Negara (BUMN) yang bergerak di bidang perkebunan kelapa sawit dan karet. Distrik Tandun adalah salah satu distrik yang memiliki 6 kebun kelapa sawit dan telah menghasilkan olahan berupa minyak sawit dan dan inti sawit. Namun dalam pengelolaannya sering kali terjadi penurunan hasil minyak sawit dan inti sawit. Hal ini terjadi karena maraknya pencurian buah kelapa sawit yang terjadi di Distrik Tandun. Lokasi pencurian buah sangat sulit terdeteksi oleh pihak terkait dikarenakan terlalu luasnya daerah perkebunan kelapa sawit yang ada pada wilayah Se- Distrik Tandun. Dari permasalahan tersebut penulis ingin melakukan penelitian yang dapat mengetahui potensi lokasi pencurian buah kelapa sawit berdasarkan data pencurian sebelumnya. Data mining adalah teknik pengolahan yang penulis pilih untuk meneliti permasalahan tersebut. Data mining adalah suatu bidang ilmu yang dapat menghasilkan sebuah informasi melalui perhitungan dari data-data lama yang sudah tidak digunakan. "Data mining adalah campuran dari statistic, kecerdasan buatan, dan riset basis data" yang masih berkembang [1]. Salah satu teknik penyelesaian permasalahan dalam data mining adalah clustering. Clustering / pengelompokan merupakan pekerjaan yang memisahkan data/vektor ke dalam sejumlah kelompok (cluster) menurut karakteristiknya masing-masing [1].

Tujuan dan manfaat dilakukannya penelitian ini adalah untuk mengetahui seberapa akurat algoritma $\neg$ K-Means clustering dalam mengelompokkan lokasi pencurian buah kelapa sawit di Distrik Tandun serta menjadikan solusi bagi PT. Perkebunan Nusantara V untuk memberikan tingkat pengamanan pada lokasi yang berpotensi tinggi terjadinya pencurian buah khususnya pada Distrik Tandun.

\section{TEORITIS}

\subsection{Algoritma K-Means}

$K$-Means merupakan salah satu metode pengelompokan data non-hierarki yang mempartisi data yang ada ke dalam bentuk dua atau lebih kelompok. Metode ini mempartisi data ke dalam kelompok sehingga data berkarakteristik sama dimasukkan ke dalam satu kelompok yang sama dan data yang berkarakteristik berbeda dikelompokan ke dalam satu kelompok yang lain. Adapun tujuan pengelompokan data ini adalah untuk meminimalkan fungsi objektif yang di set dalam suatu kelompok dan memaksimalkan variasi antar kelompok [1]. 
Dalam perhitungannya, algoritma K-Means berusaha dalam mengelompokkan sebuah data yang tersedia menjadi beberapa kelompok, dimana setiap data dalam kelompok memiliki karakteristik yang berbeda dengan data pada kelompok yang lain. Berikut langkah-langkah penyelesaian dalam algoritma K-Means :

1. Tentukan nilai $\mathrm{k}$ sebagai jumlah kluster yang ingin dibentuk.

2. Inisialisasi k sebagai centroid yang dapat dibangkitkan secara random.

3. Hitung jarak setiap data ke masing-masing centroid menggunakan persamaan Euclidean Distance yaitu sebagai berikut:

$$
\mathrm{d}(\mathrm{P}, \mathrm{Q})=\sqrt{\sum_{j=1}^{p}\left(x_{j}(P)-x_{j}(Q)\right)^{2}}
$$

4. Kelompokkan setiap data berdasarkan jarak terdekat antara data dengan centroidnya.

5. Tentukan posisi centroid baru (k).

Kembali ke langkah 3 jika posisi centroid baru dengan centroid lama tidak sama [2].

\section{ANALISA DAN PEMBAHASAN}

PT. Perkebunan Nusantara V adalah sebuah perusahaan yang memiliki kewajiban untuk memberikan peningkatan keuntungan dari sebuah perusahaan dalam pengelolaan kebun kelapa sawit dan juga karet. Salah satu tanaman yang dapat meningkatkan keuntungan yang sangat signifikan bagi pihak perusahaan adalah tanaman kelapa sawit. Dengan melakukan pengeloaan terhadap tanaman kelapa sawit yang baik dan benar akan menghasilkan buah-buah kelapa sawit tersebut menjadi sangat berkualitas. Namun pada saat pengelolaannya sering terjadi pencurian buah dari kelapa sawit yang sudah siap untuk dipanen. Salah satu factor penyebabnya dapat dlihat dari luas wilayah kelapa sawit tersebut terutama pada Distrik Tandun. Luas wilayah Distrik Tandun sendiri 29753,58 hektar yang terbagi dalam 6 kebun.

Tabel 1. Kebun Kelapa Sawit Pada Distrik Tandun

\begin{tabular}{clc}
\hline No & \multicolumn{1}{c}{ Nama Kebun } & Luas kebun (ha) \\
\hline 1 & TANDUN (TAN) & 7126 \\
2 & TERANTAM (TER) & 7860,11 \\
3 & TAMORA (TAM) & 3175,89 \\
4 & SEI KENCANA (SKL) & 4866,16 \\
5 & SEI LINDAI (SLI) & 3603,42 \\
6 & SEI BATULANGKAH (SBL) & 3122 \\
\hline
\end{tabular}

Seluruh kebun yang ada pada Distrik Tandun memiliki luas wilayah yang sangat besar. Dalam mengatasi hal tersebut, PT. Perkebunan Nusantara V membuat sebuah Afdeling atau wilayah yang sudah pecah menjadi beberapa bagian terhadap masing-masing kebun pada Distrik Tandun. Banyaknya afdeling tergantung pada luas wilayah yang ada pada kebun tersebut. Untuk data pencurian kelapa sawit, penulis mengambil 3 parameter yang akan menjadi tolak ukur dari proses pengelompokan kelapa sawit yaitu luas wilayah, diselamatkan, dan hilangnya buah pencurian.

Dalam proses algoritma K-Means Clustering yang pertama adalah menentukan jumlah cluster (kelompok) dan menentukan titik pusat cluster (centroid) awal yang bertujuan sebagai target dari seluruh data yang akan melakukan pendekatan ke seluruh centroid yang sudah di tentukan menggunakan rumus Euclidean.

1. Pemilihan Centroid

Penentuan jumlah cluster dalam penelitian ini adalah 3 cluster sesuai dengan tingkat kategori data pencurian kelapa sawit di Distrik Tandun yaitu rendah, sedang dan tinggi.

Tabel 2. Nilai Centroid Awal

\begin{tabular}{lcccc}
\hline Centroid & Fitur $\mathbf{x}$ & Fitur $\mathbf{~}$ & Fitur $\mathbf{z}$ & Kategori \\
\hline C1 & 601 & 0 & 0 & rendah \\
C2 & 804,61 & 6580 & 500 & sedang \\
C3 & 962 & 37510 & 27930 & tinggi \\
\hline
\end{tabular}

Pada table 2 dapat dilihat jumlah cluster yang sudah ditentukan sebanyak 3 dengan setiap centroidnya memiliki 3 fitur yaitu fitur x, fitur y dan fitur z. Fitur-fitur tersebut adalah variable yang diambil dari field data pencurian yaitu Luas, Diselamatkan, dan Hilang yang berfingsi sebagai parameter dari hasil clustering nantinya.

2. Iterasi Pertama

Menghitung jarak setiiap data ke centroid terdekat. Centroid yang terdekat akan menjadi cluster yang diikuti oleh data tersebut. Berikut adalah perhitungan jarak setiap data dengan rumus euclidean.

Penentuan centroid pada cluster ke-1

Data ke-1 $=\sqrt{(962-601)^{2}+(37510-0)^{2}+(27930-0)^{2}}=46767,674$ 


$$
\begin{aligned}
& \text { Data ke- } 2=\sqrt{(987-601)^{2}+(420-0)^{2}+(0-0)^{2}}=570,435 \\
& \text { Data ke- } 3=\sqrt{(945-601)^{2}+(4235-0)^{2}+(2862-0)^{2}}=5122,949 \\
& \text { Data ke- } 4=\sqrt{(390-601)^{2}+(12621-0)^{2}+(5400-0)^{2}}=13729,318 \\
& \text { Data ke- } 5=\sqrt{(\mathbf{8 9 8}-\mathbf{6 0 1})^{2}+(\mathbf{6 8 8 5}-\mathbf{0})^{2}+(\mathbf{3 9 8 4}-\mathbf{0})^{2}}=\mathbf{7 9 6 0 , 1 3 1} \\
& \ldots \\
& \text { Data ke- } 40=\sqrt{(788,44-601)^{2}+(200-0)^{2}+(50-0)^{2}}=278,628
\end{aligned}
$$

\begin{tabular}{|c|c|c|c|c|c|c|}
\hline \multirow{2}{*}{ NO. } & \multirow{2}{*}{ AFD } & \multicolumn{3}{|c|}{ Jarak Ke Centroid } & \multirow{2}{*}{ Terdekat } & \multirow{2}{*}{ Cluster yang diikuti } \\
\hline & & c1 & c2 & c3 & & \\
\hline 1 & TAN I & 46767,674 & 41341,197 & $\mathbf{0 , 0 0 0}$ & 0,000 & 3 \\
\hline 2 & TAN II & $\mathbf{5 7 0 , 4 3 5}$ & 6182,950 & 46430,094 & 570,435 & 1 \\
\hline 3 & TAN III & 5122,949 & 3331,333 & 41660,899 & 3331,333 & 2 \\
\hline 4 & TAN IV & 13729,318 & 7789,453 & 33576,635 & 7789,453 & 2 \\
\hline 5 & TAN V & 7960,131 & 3498,572 & 38875,515 & 3498,572 & 2 \\
\hline 6 & TAN VI & 384,000 & 6601,435 & 46766,286 & 384,000 & 1 \\
\hline 7 & TAN VII & 13116,169 & 8362,047 & 33655,866 & 8362,047 & 2 \\
\hline 8 & TAN VIII & 3691,236 & 7225,088 & 44596,015 & 3691,236 & 1 \\
\hline 9 & TER I & 3540,137 & 3066,629 & 43803,591 & 3066,629 & 2 \\
\hline 10 & TER II & 5208,612 & 1400,067 & 42398,755 & 1400,067 & 2 \\
\hline 11 & TER III & 4483,266 & 2119,730 & 43070,815 & 2119,730 & 2 \\
\hline 12 & TER IV & 2795,230 & 3811,833 & 44442,637 & 2795,230 & 1 \\
\hline 13 & TER V & 6602,110 & 0,000 & 41341,197 & 0,000 & 2 \\
\hline 14 & TER VI & 1630,938 & 5004,455 & 45325,378 & 1630,938 & 1 \\
\hline 15 & TER VII & 321,698 & 6446,182 & 46616,205 & 321,698 & 1 \\
\hline 16 & TER VIII & 271,089 & 6586,868 & 46647,451 & 271,089 & 1 \\
\hline 17 & TER IX & 124,133 & 6597,563 & 46751,371 & 124,133 & 1 \\
\hline 18 & TER $X$ & 61,935 & 6599,741 & 46738,127 & 61,935 & 1 \\
\hline 19 & SBL I & 268,425 & 6596,635 & 46744,886 & 268,425 & 1 \\
\hline 20 & SBL II & 262,718 & 6597,014 & 46748,477 & 262,718 & 1 \\
\hline 21 & SBL III & 198,252 & 6598,222 & 46760,593 & 198,252 & 1 \\
\hline 22 & SBL IV & 960,234 & 5644,392 & 45989,195 & 960,234 & 1 \\
\hline 23 & SLI I & 136,331 & 6592,427 & 46695,653 & 136,331 & 1 \\
\hline 24 & SLI II & 520,201 & 6583,643 & 46459,113 & 520,201 & 1 \\
\hline 25 & SLI III & 2299,428 & 6819,129 & 45436,033 & 2299,428 & 1 \\
\hline 26 & SLI IV & 27088,891 & 21513,381 & 19829,777 & 19829,777 & 3 \\
\hline 27 & SLI V & 8724,165 & 4907,555 & 38048,303 & 4907,555 & 2 \\
\hline 28 & TAM I & 74,800 & 6604,840 & 46768,311 & 74,800 & 1 \\
\hline 29 & TAM II & 303,300 & 6584,958 & 46588,809 & 303,300 & 1 \\
\hline 30 & TAM III & 1323,186 & 5306,637 & 45642,113 & 1323,186 & 1 \\
\hline 31 & TAM IV & 4541,947 & 2091,557 & 43153,117 & 2091,557 & 2 \\
\hline 32 & TAM V & 89,478 & 6597,651 & 46747,405 & 89,478 & 1 \\
\hline 33 & SKE I & 51,670 & 6603,440 & 46764,515 & 51,670 & 1 \\
\hline 34 & SKE II & 127,483 & 6480,749 & 46650,747 & 127,483 & 1 \\
\hline 35 & SKE III & 345,369 & 6263,067 & 46494,220 & 345,369 & 1 \\
\hline 36 & SKE IV & 202,783 & 6591,101 & 46648,779 & 202,783 & 1 \\
\hline 37 & SKE V & 112,089 & 6569,752 & 46742,907 & 112,089 & 1 \\
\hline 38 & SKE VI & 99,457 & 6545,262 & 46720,245 & 99,457 & 1 \\
\hline 39 & SKE VII & 0,000 & 6602,110 & 46767,674 & 0,000 & 1 \\
\hline 40 & SKE VIII & 278,628 & 6395,871 & 46576,396 & 278,628 & 1 \\
\hline
\end{tabular}

Tabel 3. Jarak Setiap Data ke Centroid Iterasi 1

\section{IMPLEMENTASI}

Untuk melakukan pengujian terhadap data pencurian buah kelapa sawit dengan menggunakan algortima k-means clustering, pengguna harus masuk ke menu proses clustering dan memilih titik pusat atau centroid yang akan dijadikan cluster/kelompok dari setiap data. 


\section{Clustering Data Pencurian}

- Clusterti.

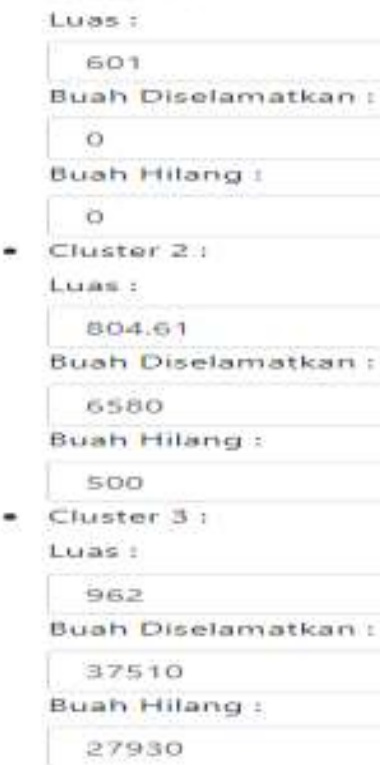

Gambar 1. Proses Pemilihan Centroid

Setelah titik pusat/centroid dari setiap cluster sudah dipilih berdasarkan analisa sebelumnya, maka pengguna dapat menekan button proses untuk melakukan perhitungan algoritma k-means clustering untk menentukan jarak dari setiap data yang sudah di implementasikan kedalam bahasa pemrograman $P H P$.

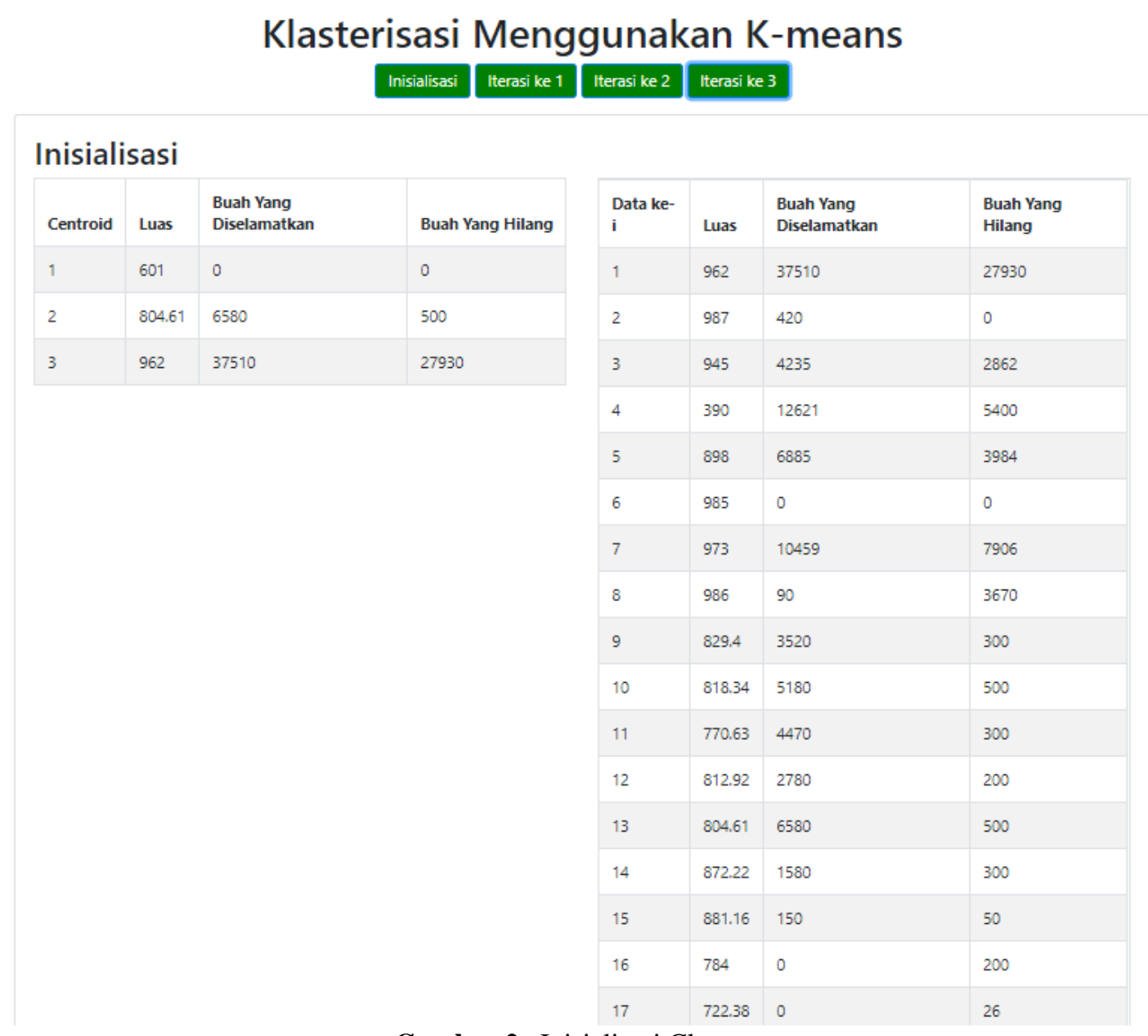

Gambar 2. Inisialisasi Cluster 


\section{Iterasi ke 1}

\begin{tabular}{|c|c|c|c|c|c|c|c|c|c|}
\hline \multicolumn{3}{|c|}{ Centroid } & Luas & \multicolumn{4}{|c|}{ Buah Yang Diselamatkan } & \multicolumn{2}{|l|}{ Buah Yang Hilang } \\
\hline \multicolumn{3}{|c|}{1} & 601 & \multicolumn{4}{|c|}{0} & \multicolumn{2}{|l|}{0} \\
\hline \multicolumn{3}{|c|}{2} & 804,61 & \multicolumn{4}{|c|}{6580} & \multicolumn{2}{|l|}{500} \\
\hline \multicolumn{3}{|c|}{3} & 962 & \multicolumn{3}{|c|}{37510} & \multicolumn{3}{|c|}{27930} \\
\hline \multirow{2}{*}{$\begin{array}{l}\text { Data } \\
\text { ke i }\end{array}$} & \multirow[b]{2}{*}{ afd } & \multirow[b]{2}{*}{ Luas } & \multirow{2}{*}{$\begin{array}{c}\text { Buah Yang } \\
\text { Diselamatkan }\end{array}$} & \multirow{2}{*}{$\begin{array}{l}\text { Buah } \\
\text { Yang } \\
\text { Hilang }\end{array}$} & \multicolumn{3}{|c|}{ Jarak ke centroid } & \multirow[b]{2}{*}{ Jarak terdekat } & \multirow[b]{2}{*}{ Cluster } \\
\hline & & & & & 1 & 2 & 3 & & \\
\hline 1 & $\begin{array}{c}\text { TAN } \\
\text { I }\end{array}$ & 962 & 37510 & 27930 & 46767,67388913 & 41341.197026841 & 0 & 0 & 3 \\
\hline 2 & $\begin{array}{c}\text { TAN } \\
\|\end{array}$ & 987 & 420 & 0 & 570.43492179214 & 6182,9496287856 & 46430,093958552 & 570.43492179214 & 1 \\
\hline 3 & $\begin{array}{c}\text { TAN } \\
\text { III }\end{array}$ & 945 & 4235 & 2862 & 5122,9488578357 & 3331,3328191731 & 41660,899390196 & 3331.3328191731 & 2 \\
\hline 4 & $\begin{array}{l}\text { TAN } \\
\text { IV }\end{array}$ & 390 & 12621 & 5400 & 13729.31760868 & 7789.4532832606 & 33576,634807556 & 7789.4532832606 & 2 \\
\hline 5 & $\begin{array}{c}\text { TAN } \\
V\end{array}$ & 898 & 6885 & 3984 & 7960.1312803245 & 3498.5715216499 & 38875.514620388 & 3498.5715216499 & 2 \\
\hline
\end{tabular}

Gambar 3. Iterasi Pertama

\section{Home phorscalistiving ciralik -}

\section{Chart Pie Pengelompokan Data}

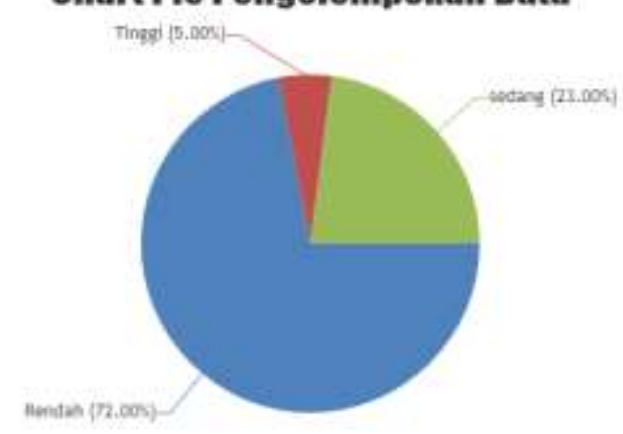

Gambar 4. Grafik Pie.

\section{KESIMPULAN}

Beberapa kesimpulan yang didapatkan pada penelitian ini, sebagai berikut:

1. Pengelompokan dengan menggunakan algoritma k-means clustering menghasilkan daerah yang rawan/berpotensi terjadinya pencurian buah kelapa sawit dengan tingkatan rendah $72 \%$, sedang $23 \%$, dan tinggi $5 \%$.

2. Cluster/kelompok yang ditentukan terhadap 3 data yaitu SKE VII, TER V, dan TAN I yang ada pada Distrik Tandun memberikan proses sebanyak 3 iterasi melalui perhitungan k-means. 


\section{REFERENCES}

[1] E. Prasetyo, Data Mining Mengolah Data Menjadi Informasi Menggunakan Matlab. yogyakarta: ANDI, 2014.

[2] A. Asroni, H. Fitri, and E. Prasetyo, "Penerapan Metode Clustering dengan Algoritma K-Means pada Pengelompokkan Data Calon Mahasiswa Baru di Universitas Muhammadiyah Yogyakarta (Studi Kasus: Fakultas Kedokteran dan Ilmu Kesehatan, dan Fakultas Ilmu Sosial dan Ilmu Politik)," Semesta Tek., vol. 21, no. 1, pp. 60-64, 2018.

[3] N. Rofiqo, A. P. Windarto, and D. Hartama, "Penerapan Clustering Pada Penduduk Yang Mempunyai Keluhan Kesehatan Dengan Datamining K-Means," KOMIK (Konferensi Nas. Teknol. Inf. dan Komputer), vol. 2, no. 1, pp. 216-223, 2018.

[4] M. G. Sadewo, A. Eriza, A. P. Windarto, and D. Hartama, "Algoritma K-Means Dalam Mengelompokkan Desa / Kelurahan Menurut Keberadaan Keluarga Pengguna Listrik dan Sumber Penerangan Jalan Utama Berdasarkan Provinsi,” Semin. Nas. Teknol. Komput. Sains, pp. 754-761, 2019.

[5] H. K. Saputra, "ANALISIS DATA MINING UNTUK PEMETAAN MAHASISWA YANG MEMBUTUHKAN BIMBINGAN DAN KONSELING MENGGUNAKAN ALGORITMA NAÏVE BAYES CLASSIFIER Hadi Kurnia Saputra 1,” J. Teknol. Inf. Pendidik., vol. 11 , no. 1 , pp. 14-26, 2018

[6] S. S. P. Luka, I. M. Candiasa, and K. Y. E. Aryanto, "ANALISIS PEMBENTUKAN KELOMPOK DISKUSI PANEL SISWA MENGGUNAKAN ALGORITMA FUZZY C-MEANS DAN K-MEANS,” J. Pendidik. Teknol. dan Kejuru., vol. 16, no. 2, pp. 267277, 2019.

[7] Y. Kusumawardani, A. Hamzah, and Suraya, "PERBANDINGAN METODE CLUSTERING MENGGUNAKAN HIERARCHICAL CLUSTERING DAN PARTITIONAL CLUSTERING UNTUK MENGELOMPOKKAN DOKUMEN BERITA,” J. Scr., vol. 5, no. 2, pp. 245-254, 2018.

[8] R. R. Putra and C. Wadisman, "IMPLEMENTASI DATA MINING PEMILIHAN PELANGGAN POTENSIAL MENGGUNAKAN ALGORITMA K-MEANS,” J. Inf. Technol. Comput. Sci., vol. 1, no. 1, pp. 72-77, 2018.

[9] Elly Muningsih and S. Kiswati, "Penerapan Metode K-Means Untuk Clustering Produ 